\title{
O ENEM E A SUBSUNÇÃO DO ENSINO DE HISTÓRIA DO AMAPÁ, ENTRE 1998 E 2015
}

\author{
JULIA MONNERAT BARBOSA* \\ EVERTON NUNES DE SOUSA** \\ RICARDO TRINDADE RODRIGUES *** \\ SABRYNNE GÓES PARENTE COLARES ${ }^{* * * *}$
}

Resumo: o estudo proposto neste artigo tem como objetivo analisar a relação entre o Exame Nacional do Ensino Médio (ENEM) e o ensino de História do Amapá. Nessa relação foram suprimidas as características constitutivas das identidades regionais e/ou locais por meio do ensino de História do Brasil. Quanto a isso, afirmamos que o Exame Nacional do Ensino Médio, devido a ser um procedimento institucional para o ingresso no ensino superior, vem desde 2009 reforçando esse movimento homogeneizador, pois subsome os conteúdos referentes à História Regional e/ou Local na História do Brasil, e essa subsunção ganha contornos mais destacados em localidades e regiões brasileiras fora do tradicional eixo da historiografia nacional: o Sudeste e o Sul do Brasil. Foi realizada uma pesquisa bibliográfica com o objetivo de refletir sobre a construção do Estado e da identidade nacional em sua relação com a História Regional e/ou Local; também foi realizada uma pesquisa sobre os instrumentos aplicados no ENEM no período de 1998 a 2015, com a finalidade de analisar as questões de História e distinguir suas matrizes conceituais, para com isso identificar o percentual de questões de História do Brasil e de História Regional e/ou Local. O estudo conclui que as questões do ENEM, gradativamente, ano após ano, são estruturadas com conteúdos de História Nacional; e isso se faz com a subsunção dos conteúdos, em nosso caso específico, de História do Amapá.

Palavras-chave: ENEM. Ensino de História Regional e/ou Local. Brasil. Amapá.

\section{ENEM and the subsumption of history teaching of Amapá, between 1998 and 2015}

Abstract: The study proposed in this paper aims to analyze the relationship between the National Secondary Education Examination (ENEM - Exame Nacional do Ensino Médio) and the Amapá history teaching. In this relation were suppressed the constitutive characteristics of regional identities and / or locations through the teaching of the history of Brazil. In this regard, it is stated that the National Secondary Education Examination, due to being an institutional procedure for admission to higher education, has since 2009 reinforcing this movement homogenizer because it suppresses content related to the Regional History and/or location, and this suppression gains more prominent contours in localities and Brazilian regions outside the traditional axis of national historiography: the southeast and south of Brazil. A literature search in order to reflect on the state-building and national identity in its relationship with the regional and / or local history was made; It was also carried out research on the instruments applied in ENEM from 1998 to 2015, in order to analyze the history of questions and distinguish

\footnotetext{
* Doutora em História pela Universidade Federal Fluminense (UFF). Professora de Metodologia do Ensino de História na da Universidade Federal do Amapá (Unifap).

** Graduado em História pela Universidade Federal do Amapá (Unifap).

*** Graduado em História pela Universidade Federal do Amapá (Unifap).

${ }^{* * * *}$ Graduada em História pela Universidade Federal do Amapá (Unifap).
} 
their conceptual matrixes for thereby identifying the percentage of history issues in Brazil and regional history and / or location. The study concludes that the ENEM issues, gradually, year after year, are structured with national history content; and this is made by the suppression of the Amapá story content.

Keywords: ENEM. Teaching of Regional and/ or Local History. Brazil. Amapá.

\section{A formação do Estado nacional no Brasil}

Hobsbawm (1990) afirma que a construção das nações foi um fenômeno que se realizou por cima, e não pode ser compreendido senão a partir dos interesses comuns das pessoas, as quais não eram necessariamente nacionais e muito menos nacionalistas. Para esse autor, a nação é um processo moderno, que se constituiu durante a era industrial. Essa construção deveria ser observada no contexto, à época, dos pontos de vista político, do desenvolvimento tecnológico, do econômico e das necessidades do aparelho administrativo onde se emergia.

Nesse processo de construção da nação, o Estado precisou assumir seu papel como agente ativo da subsunção das particularidades regionais e/ou locais em favor da coesão nacional, e, com essa finalidade, foram criados mecanismos capazes de forjar uma homogeneidade. A educação foi um desses mecanismos criados pelos Estados emergentes para descaracterizar no indivíduo a identidade, cuja marca é o pertencimento à determinada região, em prol de uma nacionalidade construída de cima para baixo.

A identidade nacional, amplamente divulgada através do movimento nacionalista, nasceu como uma espécie de novo modelo de solidariedade socialmente mediada, tornando-se um poderoso dispositivo de integração social e de legitimação de vários sistemas políticos. A inserção na economia mundial durante esse período resultou na sua integração ao sistema capitalista de maneira dependente e subordinada, devido às necessidades dos países periféricos em fornecer matéria-prima e mercado consumidor para os países que iniciavam a sua industrialização. É nesse contexto de submissão que nasce a ideia de se construir a nação e sua nacionalidade, que, no caso brasileiro, resultou em sua autonomia política, democrática e federativa (Lowy, 1995).

É nessa conjuntura histórica, de formação e independência de Estados Nacionais, que no Brasil o projeto de nação começou a ser construído. Mas diversos meca- 
nismos foram utilizados com a finalidade de garantir a predominância do nacional sobre as particularidades regionais com o intuito de assegurar a unidade territorial, evitando assim a formação de caudilhos (lideranças locais), como ocorrera na América espanhola. A principal medida utilizada para esse fim foi a criação do Instituto Histórico e Geográfico Brasileiro (IHGB), em 1838, no período imperial, cuja missão foi forjar uma identidade histórica brasileira.

Nesse sentido pretendemos analisar como, na contemporaneidade, os governos brasileiros buscaram a subsunção da História Regional e/ou Local utilizando novos mecanismos e práticas, mas com a mesma finalidade: a utilização do aparelho estatal para fazer com que o conhecimento histórico fosse instrumento de consolidação da unidade nacional, constituindo um ethos para fazer emergir uma nação a partir de uma população mesclada e heterogênea.

Em função dessa necessidade e de acordo com os objetivos do Estado, o IHGB se propôs a elaborar um grande relato da nacionalidade, que atribuiria sentido, significado e unidade ao todo imperfeito e heterogêneo da nação, garantindo a adesão e fidelidade dos cidadãos. Tratava-se de um esforço de homogeneização da sociedade no plano cultural e de erradicação da diversidade regional. A elaboração de uma narrativa nacional é um elemento central ao processo de constituição da nação, fornecendo a um território delimitado geograficamente um passado comum e uma cultura nacional, procurando subordinar e erradicar a diferença (Khaled Junior, 2010, p. 50-51).

Vale ressaltar ainda que, após séculos de sua formação social, o Estado brasileiro, como uma entidade política independente, continua a esforçar-se para forjar uma homogeneização da sociedade a partir da escrita da História, através de recentes projetos governamentais, entre eles o Exame Nacional do Ensino Médio, o ENEM, que faz parte desse esforço de construir uma única História em nível nacional. É nesse contexto que as particularidades regionais e/ou locais, as quais o Estado considera desnecessárias para construção de uma Nação, são suprimidas, fazendo com que haja uma predominância da História do Brasil sobre a História Regional e/ou Local.

Destacamos que a História Regional e/ou Local é uma metodologia de pesquisa histórica que se caracteriza pelo recorte espacial. Surgiu na Revolução Historiográfica, iniciada pela Escola dos Annales nas primeiras décadas do século XX. É importante enfatizar que não se trata de uma outra História, e sim de um método de fazer história 
privilegiando especificidades relativas a dinâmicas regionais e /ou locais.

Quando um historiador se propõe a trabalhar dentro do âmbito da história regional, ele mostra-se interessado em estudar diretamente uma região específica. O espaço regional, não estando necessariamente associado a um recorte administrativo ou geográfico, pode-se referir a um recorte antropológico, cultural ou qualquer outro proposto pelo historiador (Barros, 2004, p. 153).

O estudo da História Regional e/ou Local deve fornecer aos estudantes as competências para realizarem reflexões sobre as experiências humanas no tempo, e com isso compreenderem a realidade econômica, social e política em escala regional e/ou local em seus nexos com o nacional e o global.

Só se entende, então, metodologicamente falando, como parte de um sistema de relações que ela [região] integra. Deve, portanto, ser definida por referência ao sistema que fornece seu princípio de identidade. Assim, podese falar tanto de uma região no sistema internacional ou dentro de uma das unidades de um sistema político federativo (Barros, 2004, p. 152).

Como pode ser observado, o estudo da História Regional e/ou Local é fundamental para compreender a abrangência de determinado contexto histórico, sendo uma importante ferramenta para uso do historiador que pretende fugir dos perigos reducionistas do nacionalismo metodológico, ou seja de uma escrita da história das nações forjada por alguns intelectuais eruditos financiados pelos Estados, os quais buscam consolidar-se como poder institucional jurídico, administrativo, econômico, cultural, linguístico, militar sobre determinado território. Na primeira metade do século XIX, por ocasião da criação do Instituto Histórico e Geográfico Brasileiro, para além das questões de ordem política e econômica, a História do Brasil começou a ser escrita em meio à admiração pela civilização europeia e ao sentimento nativista, caracterizado pelo apego ao lugar de vida. Ao findar daquele século, as manipulações ideológicas, políticas e econômicas dos burocratas do estado monárquico asseguraram a subsunção desse sentimento em favor da constituição do Estado nacional brasileiro conforme ao modelo europeu.

No período pós-independência, o Estado imperial empreendeu, por um lado, reprimir com rigor as sublevações - Farroupilha, Sabinada, Balaiada, Cabanagem -, as quais expressavam os antagonismos entre os poderes regionais e/ou locais e o proces- 
so de unificação política e territorial; e, por outro lado, criar um substrato ideológico que pudesse vir a amalgamar uma população mesclada e heterogênea, e dessa maneira fazer surgir uma nação. Quanto a isso, cumpria ensinar uma história do Brasil e estabelecer uma identidade nacional.

\section{Exame Nacional do Ensino Médio}

A partir dos anos de 1990, o Brasil passou a encarar o tema da qualidade do ensino como política governamental. Essa nova forma de abordagem em relação ao ensino público brasileiro passou a ser alvo de regulação por parte do governo federal, principalmente durante os dois mandatos do ex-presidente Fernando Henrique Cardoso (1995-2002). Para que houvesse êxito era necessário modernizar o sistema que avaliava os indicadores da educação pública no País. O Governo Federal ampliou as formas de avaliação, aprimorando o Sistema Nacional de Avaliação da Educação Básica (SAEB). Esse sistema era composto por uma série de avaliações em larga escala, cujo intuito era realizar diagnósticos da situação da educação básica brasileira, identificando fatores que pudessem levar a um mau desempenho dos estudantes (INEP, 2015).

Além de medir a qualidade, havia por parte do governo federal o entendimento de que era necessário modernizar o ensino no País, para que este se adequasse às novas realidades tecnológicas desse período e pudesse se aproximar do nível de qualidade dos países desenvolvidos.

A ênfase então foi dada ao Ensino Médio, pois o governo entendia que este havia acumulado ao longo dos anos maior defasagem em relação às demandas esperadas pela sociedade. O Ensino Médio passou a ser visto como uma fase de transição para o nível superior e o momento em que o jovem se profissionaliza para iniciar sua vida no mercado de trabalho, porém tais expectativas não estavam sendo alcançadas, principalmente se comparadas com indicadores de outros países.

Em 2004, durante o Governo do ex-presidente Luís Inácio Lula da Silva (20032010), o ENEM passou a acumular outras funções. Além de avaliar como o estudante do Ensino Médio termina essa fase de sua formação, o exame passou a fazer parte da proposta de expansão nacional do ensino superior, através de uma reforma universitária, buscando teoricamente disponibilizar o acesso de pessoas de baixa renda a uma 
formação acadêmica. Para obter tal objetivo foi aprovada no Congresso Nacional a Lei n. 11.096/2005, que cria o Programa Universidade para Todos (PROUNI), em que são ofertadas bolsas de estudo integrais e bolsas de estudo parciais, de $50 \%$ e $25 \%$, em instituições privadas de ensino superior.

No ano de 2009, o MEC lançou o chamado "novo ENEM" e apresentou o Sistema de Seleção Unificado (SISU). O SISU é um sistema informatizado, coordenado pelo MEC, que utiliza a nota obtida pelos alunos concluintes do Ensino Médio no ENEM para ingressar não somente em instituições privadas, mas também em instituições de ensino superior públicas. No ano de 2010 foi publicada a Portaria Normativa n. 02, de 26 de janeiro, que institui e regulamenta o SISU. As justificativas para a criação de um sistema que substituísse os vestibulares organizados pelas próprias universidades é que, embora os mesmos tivessem qualidade em selecionar os melhores candidatos, isso gerava uma série de falhas, como a inviabilidade de estudantes em se deslocar para realizarem as provas em vários Estados, o que fazia com que poucas pessoas tivessem essas condições (Luz; Veloso, 2014).

Nessa nova fase o ENEM se tornou a porta de entrada dos estudantes do Ensino Médio para a graduação e o governo federal argumentou que o SISU traria benefícios para os estudantes de baixa renda, que poderiam, a partir daquela data, acessar vagas em universidades públicas em todos os estados do País, concorrendo em nível nacional, o que, consequentemente, levaria a uma democratização do acesso ao ensino superior. Entretanto, se faz necessário analisar as desigualdades regionais existentes no Ensino Médio evidenciadas pelo resultado dos alunos no próprio ENEM, e por mais que o estudante tenha a oportunidade em acessar uma vaga em outra região fora do seu local de moradia, indagamos: como ele conseguirá se manter caso seja aprovado (Luz; Veloso, 2014)?

Atualmente, o exame é aplicado através de provas de múltipla escolha e uma redação, sendo as provas realizadas em dois dias. No primeiro dia são aplicadas as provas de Ciências Humanas e suas Tecnologias e Ciências da Natureza e suas tecnologias, compostas por 90 questões. No segundo dia são aplicadas as provas de Linguagens, Códigos e suas Tecnologias, Matemática e suas Tecnologias, também compostas por 90 questões, além da redação, totalizando 180 questões, com a proposta de avaliar as competências desenvolvidas ao longo da educação básica do aluno. 
O Exame Nacional do Ensino Médio (ENEM) e as leis, decretos e portarias que regulam a educação no País estão inseridos em um conjunto maior de adequações do Estado Nacional diante das necessidades produtivas globais. Não por acaso, nos Parâmetros Curriculares Nacionais (PCN) o trabalho, a cidadania, a vida pessoal, cotidiana e a convivência são postos como diretrizes curriculares do Ensino Médio, com ênfase principalmente no contexto do trabalho. Historicamente, sabemos que os Estados não têm como objetivo o desenvolvimento intelectual crítico de seus cidadãos e que todas as formulações e reformas em seus sistemas educacionais são voltadas a atender às necessidades de determinado modo produtivo então hegemônico. Da mesma forma, levando em conta as especificidades do caso brasileiro, os PCN e o ENEM são importantes ferramentas para uma lenta, mas gradual, reformulação educacional brasileira.

A expressão "Ciências Humanas e suas Tecnologias", criada pelos Parâmetros Curriculares Nacionais para o Ensino Médio (PCN+EM) e implantada no ENEM, engloba as áreas de conhecimentos científicos que possuem o homem como seu principal objeto de estudo em uma relação direta com as novas tecnologias. Aos olhos menos atentos, aparentemente de acordo com as justificativas dos PCNEM, trata-se de inserir as ciências humanas de forma interdisciplinar em outros campos de conhecimento. No entanto, vale enfatizar que as ciências humanas, tais como a própria História, de longa data e, mais especificamente, a partir da escola marxista, trabalham a relação do homem com os desenvolvimentos tecnológicos que proporcionam o desenvolvimento dos modos de produção. Assim sendo,

\footnotetext{
Pode-se interpretar que essa terminologia expressa a atribuição de uma função utilitária imediata para as humanidades, pois predominam assuntos relativos a resultados da ação das Ciências Humanas para a melhoria do mundo do trabalho (gestão dos indivíduos e dos grupos, planejamento, obtenção e organização das informações, e assim por diante), enquanto escasseiam propostas para a discussão política e social do mundo do trabalho em si, se ele interessa ou não como está para o sujeito que o estuda (Cerri, 2004, p. 221).
}

Logo, o aparecimento da área de conhecimento "Ciências Humanas e suas Tecnologias", criada através de aparatos oficiais que buscam reformular o ensino educacional no Brasil, não tem como objetivo construir através da análise histórica um pensamento crítico a respeito da relação entre homem e produção. O que se pretende é 
reduzir essa reflexão crítica da realidade existente e adaptar o ensino de História às exigências do mercado. Dessa forma, a História passaria a ser mais uma ferramenta ideológica apresentando a relação entre sociedade e produção de forma positiva, harmônica e necessária ao desenvolvimento socioeconômico do país. Este é o tipo de ensino histórico pretendido pelos reformadores da educação pública com o qual os professores terão que lidar, tais como: “Determinismo tecnológico. Tecnologia, mercado, representação política, são essas coisas para as quais temos que preparar e adaptar os alunos, para que [...] não sejam excluídos" (Cerri, 2004, p. 218).

É notório perceber como o Governo Federal, através de seus instrumentos, como é o caso do ENEM, utiliza o aparelho estatal em prol da construção de uma identidade nacional brasileira. Não há, dentro dessa perspectiva, espaço para que possamos expor nossas diferenças e particularidades, as quais expressam a complexidade da realidade social e cultural de um país com a dimensão geográfica do Brasil.

A recente Medida Provisória (MP) n. 746, de 2016, instituída pelo governo do atual presidente Michel Temer, também deixa claro que essa agenda continua sendo implementada no Brasil. A MP apresenta uma proposta de reformulação com o intuito de inaugurar no País um novo Ensino Médio, sendo essa a maior mudança na educação nos últimos 20 anos, desde a Lei de Diretrizes e Base da Educação (LDB). Tal medida provisória propõe a flexibilização do Ensino Médio através da oferta de itinerários formativos diferentes, nos quais o jovem tem a oportunidade de optar por uma formação técnica profissional, dentro da própria carga horária do ensino regular, o que reduz a obrigatoriedade apenas às disciplinas de língua inglesa, língua portuguesa e matemática durante os três anos dessa etapa de ensino e aprendizagem. Para os proponentes desta MP, essas medidas visam a tornar a escola mais atrativa, reduzindo os altos índices de abandono existentes no Ensino Médio (ANPUH, 2016).

A atual reforma proposta pelo MEC encarrega aos sistemas de ensino a organização dos currículos, mantendo para si o estabelecimento de padrões de desempenho esperados para o Ensino Médio, que servirão de referência para os processos nacionais de avaliação, considerando a Base Nacional Comum Curricular (BNCC). De um lado, a MP prevê a colaboração com os entes federados, por outro reforça a centralização dos sistemas de avaliação, inflexibilidade dos currículos, aumenta as formas de controle sobre o trabalho docente, quando estreita a relação entre o que é examinado e o cur- 
rículo nacional proposto, visando supostamente à melhoria nos indicadores de desempenho. Percebemos que tais alterações feitas no Ensino Médio, além de serem antidemocráticas, estão alinhadas às políticas recomendadas pelo Banco Mundial e pelo Fundo das Nações Unidas para Infância - UNICEF, em que o Estado mais uma vez utiliza os seus aparelhos para atender ao mercado produtivo mundial (ANPUH, 2016). A utilização do Estado através de suas ferramentas legais é de suma importância nesse processo que prepara mão de obra para o mercado produtivo e ao mesmo tempo dá continuidade à construção da identidade nacional brasileira, fazendo com que a o ensino de História Regional e/ou Local perca espaço nas salas de aula.

\section{O ENEM a subsunção da História do Amapá}

O ensino de História do Amapá nas escolas da rede pública não era obrigatório até que o governo estadual sancionasse a Lei n. 1.183, em 03 de janeiro de 2008, a qual averbou a obrigatoriedade desta disciplina no Ensino Fundamental e/ou Médio. No entanto, paradoxalmente à ausência anterior desta Lei, a Universidade Federal (UNIFAP) e a Estadual (UEAP) do Amapá, no seu vestibular tradicional, exigiam no seu programa os conhecimentos históricos regionais e/ou locais. Isso fazia com que as escolas públicas possuíssem um maior interesse em ofertar em seu currículo História Regional e do Amapá, preparando assim os alunos para o vestibular. Esses conteúdos eram, então, inseridos mesmo com a ausência de Lei que os regulamentasse.

Já nas escolas da rede privada essa atenção em ministrar os conteúdos relacionados à História do Amapá era ainda maior, devido à formação dos seus alunos estar voltada para além da simples conclusão do Ensino Médio, pois consistia em uma preparação específica para o vestibular através de convênios existentes nessas instituições, pelos quais elas eram responsáveis por oferecer simultaneamente a formação no Ensino Médio e a preparação para as provas dos vestibulares e concursos públicos.

Diante desse contexto, em que as universidades públicas do Estado do Amapá exigiam o conhecimento básico de História Regional e/ou Local nos seus vestibulares como requisito para ingresso em seus cursos de graduação, as escolas da rede pública e privada eram induzidas a terem em seu planejamento pedagógico o ensino de tais conhecimentos. 
Tal fato é corroborado em entrevista realizada com os professores de História. Por questões éticas, foram utilizados pseudônimos, Educador1 e Educador2, para apresentar os relatos coletados. Em um breve perfil dessa amostra, os participantes são professores que lecionam na rede pública e privada de ensino e também em cursos preparatórios para vestibulares e concursos no estado do Amapá. Os mesmos são enfáticos em afirmar a importância dos vestibulares tradicionais para o conhecimento de História Regional e/ou Local.

\begin{abstract}
Quando havia o chamado vestibular as universidades tinham seu próprio programa, criando sua matriz curricular dentro da base curricular do ensino médio. No caso do Amapá, especificamente tem a UNIFAP e a UEAP, e havia a preocupação das duas universidades em trabalharem conteúdos da história regional, tendo bastante conteúdo envolvendo história da Amazônia e Amapá, até porque todos os temas que envolviam Amapá colonial eram acompanhados anteriormente por temas da Amazônia colonial, por exemplo: o item do programa que falava da Fortaleza de São José era antecedido pelos itens fortificações coloniais na Amazônia (Educador1, março de 2017).
\end{abstract}

No entanto, após a consolidação do ENEM em 2009 como ferramenta centralizadora de acesso ao ensino superior, os conteúdos de História do Amapá sofreram um duro revés. Como já foi citado, o ENEM prioriza a "História Geral do Brasil” e quase abandona as particularidades regionais e/ou locais. Assim que as Universidades públicas aderiram espontânea ou forçadamente ao ENEM, pelas diretrizes impostas pelo MEC e suas normas reguladoras para a educação, o ensino de História do Amapá praticamente desapareceu, o que se constatou nos relatos obtidos com o Educador2:

\footnotetext{
Quando o ENEM é implantado e se torna a partir de 2009 o único caminho para o ingresso na universidade, o que se tem é uma mudança na grade curricular. Qual é essa mudança? Não é bem uma mudança. Na verdade, é uma nacionalização do currículo na matriz curricular de história. Essa nacionalização seria da seguinte forma: dentro dos objetivos do ENEM que é de fazer um reforço para o ensino médio, qual a ideia dentro da história? É despertar a nacionalidade, despertar o valor da história nacional na vida do aluno do ensino médio, a história olhada em nível geral, ou seja, a história do Brasil, descartando as peculiaridades e histórias mais regionais e locais (Educador2, março de 2017).
}

A análise dos testemunhos destes dois professores demonstra a dimensão do impacto ocasionado no ensino História do Amapá a partir das mudanças no ENEM em 2009, pois são relatos que revelam uma vivência em todo esse processo. 
Como coloca Chervel (1990), esse é um exemplo de como o Estado utiliza os seus aparelhos para moldar e redefinir o currículo escolar de acordo com suas necessidades em determinadas épocas. Nessa direção se argumenta que outras histórias, memórias, relatos de vivências em escala regional e/ou local foram sendo subsumidos, convertendo uma miríade populacional habitante nas terras do Brasil em uma comunidade nacional.

Há um entendimento de que, contemporaneamente, o ENEM exprime uma continuidade dessa prática estatal. Argumenta-se que os componentes curriculares requeridos no ENEM aos candidatos que aspiram ingressar na educação superior manifestam uma versão atualizada do processo de formação da nação indicado em parágrafos anteriores.

A nacionalização curricular engendrada pelo ENEM reverberou nas salas de aula tanto nas escolas privadas, onde ocorreu a supressão dos conteúdos de História do Amapá, quanto nas escolas públicas, onde, apesar da legislação estadual que regulamenta a oferta dessa disciplina, houve uma rápida adesão ao conteúdo programático imposto pelo Governo Federal, como relatou o Educador1:

\footnotetext{
Antigamente tinha professor da disciplina história do Amapá que era contratado pelas escolas particulares e cursinhos para trabalhar especificamente esses conteúdos; e também no ensino médio esses conteúdos eram privilegiados. Então o que aconteceu? A escola de ensino médio, tanto da rede pública quanto da rede privada e os cursinhos, eles automaticamente adotaram esse programa do ENEM, desaparecendo as aulas de história e geografia do Amapá e os seus conteúdos (Educador1, março de 2017).
}

O ensino de História Regional e/ou Local durante o período em que havia nas universidades federais os seus próprios vestibulares seguia um programa estabelecido pela própria IFES, dentro da base curricular do Ensino Médio. No Amapá, as duas instituições públicas que realizavam vestibulares para o ingresso nos seus cursos tinham a preocupação em colocar em seus conteúdos programáticos temas relacionados ao ensino de História do Amapá e da Amazônia, como mostra o item 3.3 do Manual do candidato do vestibular 2007 da UNIFAP: "Instituições e poder na Amazônia no período colonial: as missões religiosas, a administração metropolitana e a política pombalina na Amazônia, em especial na região que compreende o atual Estado do Amapá" (UNIFAP, 2007, p. 28). 
Os conteúdos de História regional e/ou Local estiveram presentes com frequência nos vestibulares elaborados pelas universidades federais da região amazônica e a exigência desse conhecimento específico da região fazia com que as escolas do Ensino Médio tivessem atenção em ministrar tais conteúdos durante o período letivo.

\begin{abstract}
Questão 18
[...] Entre os argumentos que mantinham o vínculo do Pará com as Cortes de Lisboa impedindo o reconhecimento da Independência do Brasil em 1822, pela província nortista, considera-se:

(A) Os efetivos militares portugueses no Pará eram em maioria, o que impedia o reconhecimento da autoridade de Pedro I como Imperador do Brasil, pela Junta Governativa paraense.

(B) O movimento dos "malvados índios, cafuzos e mulatos" da cidade de Muaná impediu que as tropas enviadas pelo Imperador do Brasil instalassem um governo legalista na cidade de Belém.

(C) A violenta campanha feita pelo jornal Paraense que conclamava o povo paraense a não reconhecer a autoridade de Pedro I, como Imperador do Brasil, por ele ter usurpado o trono de D. Maria I.

(D) As navegações eram mais rápidas e regulares para a Metrópole portuguesa do que para o Rio de Janeiro, além de que o comércio era feito em torno da praça de Lisboa, do Porto ou diretamente para os portos ingleses, o que gerava muitos lucros.

(E) O novo Estado político do Brasil instalado no dia 7 de setembro de 1822 foi avaliado pelo Governo Popular do Pará, como um retrocesso às modernas relações comerciais que a província nortista mantinha com a Praça de Lisboa (UFPA, 2009, p. 8).
\end{abstract}

Havia professores da disciplina História do Amapá em escolas da rede pública e particular, além dos cursinhos preparatórios para vestibulares, que se preocupavam em repassar os conteúdos locais, pois as questões elaboradas cobravam esse conhecimento.

\footnotetext{
Questão 2

“[...] Em 1944 na cidade de Macapá, o núcleo urbano à época tinha 1.286 habitantes, o que evidenciava decréscimo, [não tinha] luz elétrica, esgoto e água encanada. Enfim, era um vilarejo decadente sem serviços e atendimentos imprescindíveis ao bem-estar coletivo e ao progresso, onde se instalou o governo amapaense, sob a indiferença de parte da população [...]" (Adaptação de Santos, F. Rodrigues, História do Amapá: da autonomia territorial ao fim do janarismo - 1943 a 1970. Macapá: Editora Gráfica O Dia S.A., 1998, p. 29).

Com base no fragmento acima e de acordo com o contexto em que se inserem as ações políticas e sociais do governo do interventor Janary Nunes, responda:

a) Qual o slogan usado por Janary para definir o seu programa de organização e desenvolvimento do Território Federal do Amapá?

b) Que medidas foram tomadas por Janary Nunes, em decorrência da situação de decadência em que se encontrava o vilarejo de Macapá e da pouca
} 
expressividade populacional existente na região? (UEAP, 2009, p. 3).

\section{Questão 3}

Marquês de Pombal e Getúlio Vargas: governantes de épocas diferentes, que se preocuparam com a ocupação da Amazônia.

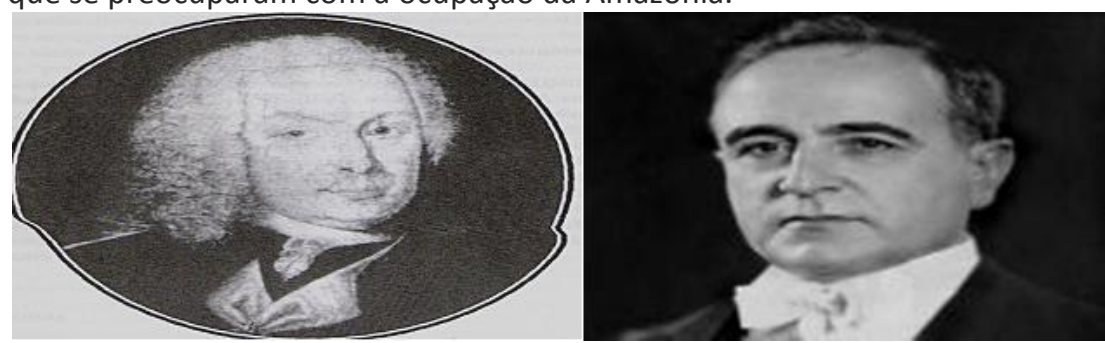

Observe os personagens da figura acima, relacione-os com o contexto histórico da região Amazônica e faça o que se pede:

Cite duas (02) estratégias ou ações, traçadas por Marquês de Pombal, para a expansão econômica e a ocupação do território amazônico, no século XVIII, com o objetivo de integrar a Amazônia à economia do Império Português.

Assim como Marquês de Pombal, Getúlio Vargas pôs em prática uma política de integração do Brasil Central e da Amazônia ao restante do País. Nesse contexto, qual era o slogan utilizado para implementar essa política e que plano foi projetado pelo presidente Vargas a partir do Discurso do Rio Amazonas em 1940?

Que medidas administrativas foram tomadas por Pombal, no século XVIII, e por Vargas, na década de 1940, que contribuíram para o surgimento do atual Estado amapaense? (UNIFAP, 2009, p. 9).

As questões acima evidenciam que, durante os vestibulares organizados pela própria universidade estadual (Universidade Estadual do Amapá), havia uma preocupação em colocar nas suas provas questões que levassem em consideração fatos históricos da nossa região, Estado ou cidade.

Dessa forma foi cobrada dos estudantes uma História além das contadas nos livros didáticos ou do que era exigido nos currículos através do aparelho estatal do Governo Federal, o que acabava rompendo com a política de construção da identidade nacional e subsunção das particularidades. No ENEM 2009, por exemplo, foram 10 questões que trataram de História do Brasil, e entre elas não houve espaço para a História Regional e/ou Local, e sim para a construção da identidade brasileira, como mostra a questão abaixo:

\section{Questão 59}

Para Caio Prado Jr., a formação brasileira se completaria no momento em que fosse superada a nossa herança de inorganicidade social - o oposto da interligação com objetivos internos - trazida da colônia. Este momento alto estaria, ou esteve, no futuro. Se passarmos a Sérgio Buarque de Holanda, encontraremos algo análogo. O país será moderno e estará formado quando superar a sua herança portuguesa, rural e autoritária, quando então tería- 
mos um país democrático. Também aqui o ponto de chegada está mais adiante, na dependência das decisões do presente. Celso Furtado, por seu turno, dirá que a nação não se completa enquanto as alavancas do comando, principalmente do econômico, não passarem para dentro do país. Como para os outros dois, a conclusão do processo encontra-se no futuro, que agora parece remoto.

(SCHWARZ, R. Os sete fôlegos de um livro. Sequências brasileiras. São Paulo: Cia. das Letras, 1999 - adaptado).

Acerca das expectativas quanto à formação do Brasil, a sentença que sintetiza os pontos de vista apresentados no texto é:

A) Brasil, um país que vai pra frente.

B) Brasil, a eterna esperança.

C) Brasil, glória no passado, grandeza no presente.

D) Brasil, terra bela, pátria grande.

E) Brasil, gigante pela própria natureza (ENEM, 2009, p. 19).

Com as mudanças ocorridas no ENEM a partir de 2009, sendo o exame utilizado como forma de ingresso de alunos ao curso das Instituições Federais de Ensino Superior, aconteceu também uma mudança na grade curricular do Ensino Médio e os conteúdos de História passaram a sofrer um processo de nacionalização, o que teve um reflexo direto nas salas de aula.

O ensino de História Regional e/ou Local praticamente desapareceu das salas de aula e dos conteúdos repassados nos cursinhos pré-vestibulares. Isso ocorreu apesar de a LDBEN estabelecer que se seguisse a matriz nacional, porém com uma parte dos conteúdos sendo escolhidos livremente pelas escolas.

Esse programa de nacionalização do currículo escolar do Ensino Médio reflete uma série de mudanças que já vem ocorrendo desde o início dos anos 2000, com diversas alterações ao longo dos anos, aprofundadas a partir de 2009; e para que isso ocorra vários mecanismos têm sido implementados por parte do Governo Federal.

Em 2011, através do parecer CNE/CEB n. 5/2011, as Diretrizes Curriculares Nacionais do Ensino Médio (DCN-EM) foram atualizadas. Apesar de as DCNEM 2011, através dos Parâmetros Curriculares Nacionais, não trazerem muitas novidades sobre como se dá a organização curricular do Ensino Médio, ficou claro que houve mudanças na linguagem e nos referenciais teóricos que foram repassados em sala de aula. O que se observou a partir desse momento foi um currículo que, em tese, tentava associar uma parte unitária (nacional) com uma parte diversificada (regional e/ou local) (MEC, 2011).

Os impactos ocorridos no ensino da História Regional e/ou Local foram grandes 
diante de uma política pública educacional centralizadora voltada com seus aparatos legais, tais como os PCNEM, ENEM, LBD, entre outros, para atender à dinâmica do mundo produtivo capitalista, não existindo lugar para as especificidades regionais e/ou locais das regiões afastadas dos grandes centros econômicos do Brasil. Se o ensino de História do Amapá por si só já encontrava grandes barreiras para se firmar como ferramenta no processo de conhecimento histórico que identificasse nosso passado, e assim permitisse compreender nossa realidade cotidiana, com as políticas públicas já citadas aqui, essa tarefa se colocou ainda mais longe e difícil de realizar.

A subsunção do ensino de História Regional e/ou Local provocada por políticas públicas que visam à nacionalização do currículo da educação no País, tem como uma de suas consequências a fragilidade no pensamento histórico, uma vez que esse conhecimento não pode ser observado apenas de maneira macro, como se os fatos históricos se dessem de forma homogênea e vertical, com uma História hierarquizada e voltada aos grandes centros econômicos do País, como pretende o ENEM.

Essa fragilidade decorre da distância entre o indivíduo e sua realidade cotidiana, onde ele não se percebe como sujeito e nem como parte do processo histórico existente no seu dia a dia. Diante de uma História Nacional, que busca forjar o pertencimento da nacionalidade, o aluno passa a enxergar a História de forma linear, desconsiderando que o conhecimento histórico se constrói a partir do micro para o macro, levando em consideração que as particularidades Regionais e/ou Locais estão relacionadas como um todo, e não podem ser analisadas de forma isolada, ocasionando uma fragilidade no seu conhecimento histórico Regional e/ou Local.

Neste contexto de subsunção do ensino de História do Amapá há uma série de desafios a serem vencidos, para que não se tenha a construção de um pensamento histórico frágil. Apesar da existência da Lei Estadual n. 1.183/2008, que autoriza o poder executivo a implantar nas escolas de Ensino Fundamental e/ou Médio a disciplina História do Amapá, esta não é aplicada de fato nas salas de aula. Existe atualmente a disciplina Estudos Amapaenses, a qual engloba conhecimentos básicos de História e Geografia do Amapá e pode ser ministrada tanto por professor formado em História como em Geografia, sendo ofertada somente para as séries iniciais do Ensino Fundamental (AMAPÁ, 2008).

Assim fica clara a existência no Ensino Médio de uma lacuna no que diz respeito 
ao ensino de História do Amapá, pois não há de fato o cumprimento desta Lei. Uma consequência dessa desvalorização é que potencialidades no ensino de História do Amapá ainda não são desenvolvidas, já que na prática a disciplina Estudos Amapaenses, além de poder ser ministrada por profissionais que não são da área de História, também não é uma disciplina específica voltada para a historiografia amapaense, o que a torna ineficaz.

Cabe a cada historiador resistir a essas investidas do mercado produtivo, onde o ensino de História deixa de fazer uma análise crítica da nossa sociedade e passa apenas a ver a lógica do mercado. O professor possui papel fundamental na luta contra essa desvalorização das particularidades históricas regionais e/ou locais imposta pelo Estado através de suas políticas públicas educacionais, diminuindo assim a fragilidade na formação do pensamento histórico e evitando o não desenvolvimento de potencialidades no ensino de História. Isso se faz através de uma releitura crítica do professor aos conteúdos oficiais impostos. Mesmo diante da imposição de um ensino voltado para fatos históricos mais gerais e nacionais, é possível ao professor retomar dentro de sua contextualização crítica o ensino da História de sua Região e/ou Localidade sem prejuízos à História Nacional. Essa é uma das formas de resistência que podem e devem ser utilizadas pelo professor de História em sala de aula. Se a História Local, segundo Samuel (1990), deve ser encontrada dobrando a esquina e descendo a rua, então cabe ao professor promover esse encontro entre o aluno e sua realidade histórica cotidiana.

\section{REFERÊNCIAS}

AMAPÁ. Lei n. 1.183, de 03 de janeiro de 2008. Autoriza o Poder Executivo a instituir no Ensino Fundamental e/ou Médio da Rede Pública Estadual de Ensino a Disciplina História do Amapá. Macapá, 2008.

ANPUH. Nota da associação nacional de história sobre a MPV 746/2016. Disponível em: <http://site.anpuh.org/index.php/2015-01-20-00-01-55/noticias2/noticias-desta que/item/4014-nota-anpuh-reforma-ensino-medio-nota-da-associacao-nacional-dehistoria-sobre-a-reforma-do-ensino-medio>. Acessado em: 17 maio 2017.

BARROS, José D’ Assunção. O campo da História: especialidades e abordagens. Petrópolis: Vozes, 2004.

BRASIL. Câmara de Educação Básica. Resolução n. 3, de 26 de junho de 1998. Institui as Diretrizes Curriculares Nacionais para o Ensino Médio. Disponível em: <http://por tal.mec.gov.br/cne/arquivos/pdf/rceb03_98.pdf>. Acessado em: 10 abr. 2017. 
Lei n. 9.394, de 20 de dezembro de 1996. Institui a Lei de Diretrizes e Bases da Educação Nacional. Brasília: MEC, 1996.

Parâmetros curriculares nacionais: ensino médio. Brasília: Secretaria de Educação Média e Tecnológica, 1999.

PCNs + Ensino Médio: orientações educacionais complementares aos Parâmetros Curriculares Nacionais. Brasília: MEC/Secretaria de Educação Média e Tecnológica, 2002.

CAPRINI, Aldieris Braz Amorim. Pesquisa em história regional: aspectos conceituais e metodológicos. III Simpósio ILB, v. 12, n. 1, p. 1-16, 2010.

CARDOSO, Ciro F. S. Agricultura, escravidão e capitalismo. 2 ed. Petrópolis: Vozes, 1982.

CARDOSO, Maria Angélica. História das disciplinas escolares e cultura escolar: Apontamentos para uma prática pedagógica. Mato Grosso: UFMS, 2006.

CERRI, Luiz Fernando. Saberes históricos diante da avaliação do ensino: nota sobre os conteúdos de história nas provas do Exame Nacional do Ensino Médio - Enem. Revista Brasileira de História, São Paulo, v. 24, n. 48, p. 213-231, 2004.

CHERVEL, André. História das disciplinas escolares: reflexão sobre um campo de pesquisa. Teoria \& Educação, v. 1, n. 2, p. 177-229, 1990.

DIAS, Liliane de Jesus; ANDRADE, Vanilza da Costa; LIMA, Gláucia Maria de Jesus. Estado-Nação: a emergência da identidade nacional para a consolidação do Estado no Brasil. Sergipe, 2009.

FAORO, Raymundo. Os Donos do Poder: Formação do patronato político brasileiro. 3. ed. Porto Alegre: Editora Globo, 2001.

FREITAS, Dirce Nei Teixeira de. Avaliação da educação básica e ação normativa federal. Cadernos de Pesquisa, v. 34, n. 123, p. 663-689, set./dez. 2004.

GUIMARÃES, Manoel Luis Salgado. Nação e civilização nos trópicos: O Instituto Histórico e Geográfico Brasileiro e o projeto de uma História Nacional. Estudos Históricos, v. 1, n. 1, p. 5-27, 1988.

HADDAD, Sérgio. Introdução. In: HADDAD, Sérgio (Org.). Banco Mundial, OMC e FMI: o impacto nas políticas educacionais. São Paulo: Cortez, 2008. p. 7-13.

HOBSBAWM, E. J. A era das revoluções. 9. ed. São Paulo: Paz e Terra, 1996.

Nações e Nacionalismo desde 1780: programa, mito e realidade. Rio de Janeiro: Paz e Terra, 1990.

KHALED JUNIOR, Salah. H. Horizontes identitários: a construção da narrativa nacional brasileira pela historiografia do século XIX. Porto Alegre: EDIPUCRS, 2010.

LE GOFF. J. A história nova. Trad. Eduardo Brandão. São Paulo: Martins Fontes, 1990.

LIMA, Ivana Stolze. História nacional, língua nacional e o povo mesclado e heterogêneo. In: NEVES, Lucia, Maria Bastos Pereira das, et al. Estudos de historiografia brasileira, Rio de Janeiro: Editora da FGV, 2011. p. 165-182.

LOWY, Michael. A teoria do desenvolvimento desigual e combinado. Revista Actuel Marx, v. 1, n. 18, p. 1-12, 1995.

MARX, Karl. O capital: crítica da economia política. Livro 1: O processo de produção capitalista. 2. ed. Rio de Janeiro: Civilização Brasileira, 1971.

MEC (Ministério da Educação). Portaria n. 438, de 28 de maio de 1998. Institui o Exame Nacional do Ensino Médio (ENEM). Brasília: MEC, 1998.

. Parecer CNE/CEB n. 5, de 4 de maio de 2011. Diretrizes Curriculares Nacionais

para o Ensino Médio. Brasília: MEC, 2011. 
MENDES CATANI, Afrânio; PAULA HEY, Ana; DE SOUSA PORTO GILIOLI, Renato. PROUNI: democratização do acesso às Instituições de Ensino Superior? Curitiba: UFPR, 2006. NORONHA DA LUZ, Jackeline Nascimento; MERTENS AGUIAR VELOSO, Tereza Christina. Sistema de seleção unificada (SISU): Refletindo sobre o processo de seleção. Dourados: Revista Educação e Fronteiras, 2014.

SAMUEL, Raphael. História Local e História Oral. Revista Brasileira de História, v. 9, n. 19, p. 219-242, 1990.

SANTOS, Milton. Por uma geografia nova: da crítica da geografia a uma geografia crítica. São Paulo: Hucitec, 1978.

SILVA, Marcos A. da (Org.). República em Migalhas: História Regional e Local. São Paulo: Marco Zero, 1990.

SILVEIRA, Rosa M. G. O regionalismo nordestino: existência e consciência da desigualdade regional. São Paulo: Moderna, 1984.

TOLEDO, Maria Aparecida Leopoldino Tursi (Org.). A disciplina de História no Império Brasileiro. Revista Histedr, v. 1, n. 17, p. 1-10, 2005.

UEAP (Universidade Estadual do Amapá). Caderno de Questões - Processo Seletivo 2009. Macapá: UEAP, 2009.

UFPA (Universidade Federal do Pará). Caderno de Questões - Processo Seletivo 2009. Belém/Pará: UFPA, 2009.

UNIFAP. Caderno de Questões - Processo Seletivo 2009. Macapá: UNIFAP, 2009. - Manual do candidato - Processo Seletivo 2007. Macapá: Departamento de Processos Seletivos e Concursos, UNIFAP, 2007. Disponível em: <https://depsec.unifap. br/antigos/Manual_Candidato_PS_2007.pdf>. Acessado em: 10 mar. 2017.

VISCARDI, Claudia Maria Ribeiro. História, Região e Poder: a busca de interfaces metodológicas. Locus, v. 3, n. 1, p. 84-97, 1997.

VITORIANO, Bruno Daniel. Nacionalismo, democracia e participação política. XXIV Semana de Ciências Sociais: Desafios Contemporâneos. Londrina/PR, 22-24 maio 2013. 